\section{Representações religiosas na experiência com a enfermidade: um estudo de caso}

\author{
Religious representations in illness experience: \\ a case study
}

Representaciones religiosas en la experiencia con la enfermedad: un estudio de caso

\section{Resumo}

Este artigo, subproduto de uma pesquisa mais ampla, aborda um estudo de caso de um adoecido de hipertensão e de problemas cardíacos que professa a religião das Testemunhas de Jeová. Mediante entrevistas com roteiro semiestruturado reconstituíram-se os relatos do entrevistado sobre a experiência com o adoecimento: diagnóstico, tratamentos e cura, enfocando as representações sociais religiosas que o permeiam, fornecendo sentido à própria vida e aos sofrimentos e às perturbações físicas e morais implicadas neste processo.

Cura pela Fé; Processo Saúde-Doença; Religião
Marco Antonio Alves Separavich 1 Ana Maria Canesqui 1
1 Faculdade de Ciências Médicas, Universidade Estadual de Campinas, Campinas, Brasil.

\author{
Correspondência \\ M. A. A. Separavich \\ Faculdade de Ciências \\ Médicas, Universidade \\ Estadual de Campinas. \\ Rua Tessália Vieira de \\ Camargo 126, Campinas, SP \\ 13083-970, Brasil. \\ mseparavich@hotmail.com
}




\section{Introdução}

Os estudos socioantropológicos sobre os elos entre religião, saúde, doença e cura mostram que a religiosidade é um recurso usado pelas pessoas para resolver ou aliviar os problemas de saúde, aflições e sofrimentos 1,2,3,4,5,6. Concebe-se a religião como sistema simbólico portador de um conhecimento sobre o mundo, por meio do qual as pessoas atribuem sentido à realidade vivida 1 .

As religiões possibilitam aos sofredores, e para aqueles que com eles convivem, reinterpretar a experiência do adoecimento e da cura, restabelecendo a ordem num universo aparentemente sem sentido, conturbado pelos sofrimentos, aflições e doenças 1,2 .

Estudos tematizam os tratamentos religiosos e as reinterpretações dos seus participantes sobre o processo saúde-doença e cura 2,4,6, a importância da corporalidade nos rituais de cura 7 , os percursos religiosos dos adoecidos na busca da resolução de suas aflições e problemas de saúde e a fluidez das religiosidades na contemporaneidade 5,7.

As religiões de matriz africana, como a Umbanda e o Candomblé 2,3,4,6, e as derivadas do Protestantismo, como as Pentecostais e Neopentecostais 5,7 receberam maior atenção dos pesquisadores pelo fato de as primeiras apresentarem laços fortes na modelagem da cultura popular e nos tratamentos tradicionais de cura, e as últimas devido ao aumento crescente dos seus adeptos, que, invariavelmente, as procuram na busca de resolução dos seus sofrimentos, aflições e doenças.

Neste estudo de caso analisam-se a experiência e as representações religiosas de um adoecido de hipertensão e doença cardíaca, Testemunha de Jeová, segmento religioso cristão pouco estudado, sob o olhar socioantropológico do processo saúde-enfermidade.

O movimento religioso das Testemunhas de Jeová surgiu nos Estados Unidos, em 1872, como ramo dissidente do Presbiterianismo. É uma doutrina com contornos do puritanismo calvinista, difundido pelos primeiros colonizadores da América inglesa. No Brasil, os religiosos se estabeleceram na década de 1920, dando-se os primeiros batismos em 1922, e em 1931, criou-se uma congregação pioneira no Amazonas, com setenta pessoas. Atualmente, registram-se mais de 600 mil fiéis brasileiros. O Brasil é o segundo maior praticante desta religião, antecedendo-lhe os Estados Unidos 8 .

As Testemunhas de Jeová endossam a verdade única revelada na Bíblia que norteia as condutas, ordenadas pela própria divindade. Entre suas incumbências religiosas está a de preparar as pessoas para a segunda vinda de Jesus, sele- cionando os justos para a salvação, restaurando, assim, o verdadeiro Cristianismo. Consideram-se proclamadores e testemunhas da verdade de Jeová (nome de Deus em português), conforme grafado pelo tetragrama bíblico "Y-H-V-H" 8. Neste contexto, as representações religiosas revelam as conexões íntimas entre salvação e saúde, modelando a experiência moral com o adoecimento.

\section{Metodologia}

Este estudo integra a tese de doutoramento ${ }^{9}$ que analisou as representações e experiências de homens trabalhadores com o corpo, saúde e doença. Mediante roteiro semiestruturado, entrevistaram-se 15 homens em suas residências, com média etária de 56 anos, moradores de um bairro popular do Município de Campinas, São Paulo, Brasil.

Selecionou-se o caso baseado em sua singularidade: o informante foi o único que declarou professar a religião das Testemunhas de Jeová. Ele convive com uma das enfermidades prevalentes informadas pelo grupo entrevistado: a hipertensão arterial.

A hipertensão arterial sistêmica, a "pressão alta” como, popularmente, é designada, atinge $35 \%$ da população jovem e adulta brasileira, sendo assintomática, de origem multifatorial, crônico-degenerativa e fator de risco para outras enfermidades como as cardiovasculares, renais e cerebrovasculares, segundo a biomedicina. Representa-se, nos estratos populares, como doença "grave”, "silenciosa”, "traiçoeira” e "perigosa" 10, capaz de matar sem dar sinais prévios. Para analisar as representações religiosas do informante, que incidem e modelam a sua experiência com o adoecimento utilizaram-se os aportes teóricos da experiência da enfermidade e das representações sociais.

Entende-se a experiência da enfermidade como abordagem teórica e conceitual, utilizada nas pesquisas sociantropológicas do processo saúdedoença no mundo anglo-saxão, privilegiando-se o ponto de vista dos adoecidos 11 . Analisa-se a forma como eles dão sentido às enfermidades no curso do adoecimento, como lidam com as restrições físicas e sociais, o diagnóstico e os tratamentos, e como evitam a deterioração de suas identidades diante delas 12

De um lado, trata-se de um recorte temporal preciso na vida daquele que sofre, não sendo, consequentemente, expressão definitiva da experiência da sua vida, nem tampouco, abrangentemente, da própria enfermidade, pois esta se altera no tempo e espaço, mediante o seu curso, a variação das condições de saúde e vida do in- 
formante. De outro, a experiência é relatada e sujeita às interpretações, mediadas pela interação social e pelos ditames da consciência e memória de quem a informa.

Os relatos permeiam-se de representações sociais, entendidas por Laplantine 3 (p. 43) como a conjugação “[da] experiência individual e [dos] modelos sociais num modo de apreensão particular do real", em que se apresentam crenças, valores e conhecimentos que informam e dão sentido à ação. Para explicitar a imbricação das representações sociais, sobretudo religiosas, na experiência do entrevistado com o seu adoecimento recorreu-se ao estudo de caso, como fora desenvolvido por outros pesquisadores 10,13.

Segundo Stake 14, o caso é uma unidade recortada, um sistema delimitado cujas partes se integram. O estudo de caso delimita o objeto a ser estudado, sem desprezar o contexto maior em que ele se insere: histórico, psicológico, social, econômico, cultural. A sua análise permite transcender a experiência pessoal e subjetiva informada, possibilitando dialogar com o contexto social mais amplo ${ }^{10}$. O estudo baseia-se num número restrito de questões, importando ao pesquisador tornar clara a sua compreensão e não generalizar os seus resultados.

Para este estudo usaram-se questões pontuais de um roteiro: o perfil socioeconômico, demográfico e ocupacional do entrevistado, o significado e convívio com a doença, a descoberta da doença, explicações de suas causas, a relação e significação dos tratamentos utilizados e o modo como o adoecimento repercute em sua rotina de vida.

Transcritos, lidos flutuantemente e organizados os relatos orais do sujeito extraídos das entrevistas, a análise de conteúdo de Bardin 15 permitiu identificar temas, textos e núcleos de sentido, que denotam significações, simbologias, valores, ao lado dos que expressam modos de agir, de enfrentar a enfermidade e suas implicações na vida cotidiana, permitindo compreender e interpretar as representações e a experiência circunscrita da enfermidade.

O projeto de pesquisa foi aprovado pelo Comitê de Ética da Faculdade de Ciências Médicas, Universidade Estadual de Campinas, parecer no 274078/13, CAAE 12855613.4.0000.5404.

\section{Jair: perfil e a descoberta da hipertensão e da doença cardíaca}

Jair, nome fictício, 51 anos, nasceu em Campinas, é casado e tem três filhos. É mecânico de automóveis com registro em carteira profissional; recebe mensalmente dois salários mínimos, que, somados aos salários da esposa e do filho mais velho perfazem uma renda familiar de aproximadamente cinco salários mínimos mensais. Trabalha seis dias por semana, folgando um sábado por mês.

Concluiu o Ensino Médio, residindo no bairro, desde pequeno. O local possui equipamentos sociais, de saúde, educação, creche, uma pequena rede de comércio e serviços, uma Igreja Católica e vários espaços religiosos Pentecostais e Neopentecostais. Jair é Testemunha de Jeová desde jovem, religião professada por seus pais e irmã.

Seus problemas de saúde começaram há cinco anos, quando percebeu um "formigamento" nas mãos, nos braços e dores no peito, provocando a sensação de falta de força física, observada quando percorria diariamente a passarela para acessar o outro lado da pista rodoviária que corta o bairro, para tomar o ônibus que o leva ao serviço.

Afora esses sinais corporais, relata dor de cabeça constante, uma espécie de enxaqueca que o fazia consumir, mensalmente, várias cartelas de aspirina. Esses fatos motivaram a sua ida ao Posto de Saúde:

"Fui ao médico, conversei com ele, ele pediu uma série de exames, deu insuficiência cardíaca. Ele falou: 'precisa fazer cirurgia'. Falei, espera aí, eu não vou fazer direto (...) Conversei com um amigo médico que atende em um hospital do SUS [Sistema Único de Saúde]. Fui lá, ele fez os exames que acusaram também (...) Voltei e me deram um encaminhamento para o Hospital da PUCC [Pontifícia Universidade Católica de Campinas]. Fiz o restante dos exames e cateterismo. O médico falou: 'você está com quatro veias entupidas em 95\%. Você não pode pensar em correr'. Ele falou: 'do jeito que está aqui, se der um ataque você não resiste...".

Para Jair, a sua situação de saúde era crítica: não conseguiu fazer o exame ergométrico para avaliar o funcionamento cardiovascular. Submeteu-se ao exame por contraste, em que se injeta uma solução à base de iodo orgânico na corrente sanguínea e monitora-se com um aparelho o desempenho cardíaco por meio de imagens 16 , permanecendo deitado. Ao diagnóstico médico seguiu-se um período de oito meses de providências dos exames para realizar a cirurgia. Foi quando descobriu ser hipertenso, tendo iniciado o uso de medicação contínua para controlar a doença.

Considera-se um "homem de sorte", porque, apesar de seu histórico familiar de doenças cardíacas - o pai já sofreu infarto e tem duas pontes de safena e uma mamária e os avós paternos faleceram destes males - conseguiu levar uma vida 
normal, sem saber que poderia ter morrido de uma hora para outra, conforme avalia:

"O médico falou que eu estava com uma deficiência muito forte do lado esquerdo do coração, $e$ que não tive um ataque cardíaco porque tomava aspirina todo dia. Eles falam que isso ajuda. Mas, eu jogo bola com a molecada, falei para ele, eu corro! Ele falou: "você corria o risco de cair morto no campo e ninguém saber o porquê"'.

Anteriormente à doença cardíaca, Jair se considerava uma pessoa saudável, embora fizesse, eventualmente, o exame de eletrocardiograma e praticasse esporte. Desconhecia a sua predisposição familiar para "pressão alta", afirmando que:

"De vez em quando eu fazia um exame, fazia check up, ia ao posto, fazia o eletrocardiograma, vivia normal, trabalhava, jogava bola, me sentia bem. Mas, fazia um tempo que eu não fazia, aí medi a pressão e estava 12 por 8, 13 por 9, sempre assim, não alterava, e o médico falava: 'está normal, a pressão sua está excelente!'. Depois que eu comecei a sentir isso [dores no peito], o médico mediu e falou: 'a sua pressão subiu um pouco, está 15 por 10'. Da outra vez falou: 'está 16 por 11'. Isto para mim foi novidade".

Diferentemente do entendimento biomédico, Jair não vê a sua doença cardíaca como decorrente da hipertensão arterial, mas o inverso, surpreendendo-se com o diagnóstico.

\section{Explicações das causas das enfermidades}

À hereditariedade Jair atribui o desenvolvimento dos seus problemas cardíacos e da "pressão alta", como também ao regime alimentar inadequado, confessando: "não como verdura verde e nem peixe de jeito nenhum". Acrescenta o estresse e o "nervoso" vividos cotidianamente e o fato de ter sido fumante durante um longo tempo. Estes elementos explicativos afinam-se ao discurso biomédico da causa, tanto dessas quanto de outras enfermidades, como o diabetes ${ }^{13}$, expressos por ele da seguinte forma:

"Conversando com o médico ele falou: 'Isso aí é porque você fumou, uma boa porcentagem - ele falou-50\% é hereditário, um pouco é o estresse da profissão e a correria do dia a dia, então juntou tudo, como você nunca fez aquela dieta alimentar resultou nisto"'.

"A pessoa que fica preocupada e nervosa o tempo todo tem tendência a esses problemas, porque eles alteram o corpo dela. Eu sempre fui assim: um cara que teve uns problemas que não tinha como resolver e ficava preocupado".

Entre as causas aludidas pelo entrevistado, ressalta-se o "nervoso" como categoria físicomoral, no sentido atribuído por Duarte 17: a ideia de que eventos afetivos e morais conflituosos se refletem no organismo, na fisicalidade das pessoas e vice-versa.

Neste sentido, a noção dos "nervos" entre as classes trabalhadoras, segundo Duarte 17, expressa a qualidade eminentemente relacional das experiências emocionais vividas aflitivamente e as enfermidades somáticas, ambas indivisíveis na vida da pessoa. Distancia-se, portanto, do significado psíquico, autônomo e individualista, assumido pela relação corpo/mente na biomedicina.

Salienta-se, também, a simbologia atribuída ao coração, popularmente concebido como sede da vida e das emoções. No cerne destas representações está a importância vital do sangue, acreditando que as preocupações e aflições vividas cotidianamente afetam o seu fluxo entre os órgãos, fazendo-o concentrar-se no coração, na cabeça ou em certas partes do corpo, provocando desequilíbrio no funcionamento corporal e enfermidades decorrentes 18 .

Embora a hereditariedade componha o repertório causal da enfermidade informada por Jair, não se trata apenas da assimilação do discurso médico hegemônico, pois a ele se sobrepõem os valores morais e explicações advindas da sua religião, refletidos na forma como representa o processo saúde-enfermidade.

Os valores morais exigidos das Testemunhas de Jeová encontram no enredo dramático bíblico o modelo de conduta. Ali é contada a origem, a queda e a redenção do homem, fornecendo explicações para a causa de suas dores, aflições e sofrimentos, sem negar a esperança de um porvir feliz.

Várias publicações das Testemunhas de Jeová dirigidas ao público em geral reafirmam tais valores. Dentre elas O Que A Bíblia Realmente Ensina 19 , que nos foi presenteada pelo informante, à qual recorremos para reportar o conteúdo da doutrina religiosa por ele professada, particularmente, na relação estabelecida entre a cosmologia informada e o processo saúde-enfermidade.

Dois momentos da narrativa bíblica são importantes para o fiel: (1) a queda de Adão e Eva, primeiros humanos criados por Jeová, que tentados pelo diabo desobedeceram ao mando divino de não comer da árvore proibida do Bem e do Mal, resultando na expulsão de ambos do paraíso e na introdução da vida humana, antes perfeita e imortal, do sofrimento, do pecado e da morte; (2) o nascimento do filho unigênito de Jeová entre os homens, Jesus Cristo, com a missão divina de restabelecer os laços rompidos com Deus pelos pais da humanidade, possibilitando, assim, a salvação e vida eterna a todos. Ao dar a sua vida em sacrifício, Jesus estabeleceu o caminho à redenção 19. 
Esses elementos explicativos dos infortúnios humanos, integrantes do relato de Jair, fundamentam as explicações religiosas na origem dos sofrimentos e doenças:

“A gente, como Testemunha de Jeová, sabe que os problemas são uma consequência. Tudo o que passamos hoje é consequência do princípio, porque Deus queria que todo mundo fosse perfeito e vivesse para sempre. O homem recusou isso. Então, o que ele trouxe para ele? O pecado, a morte, a doença. Por que a gente sofre e morre? Porque lá no princípio o homem pecou contra Deus que disse: 'a partir de hoje você vai morrer, você vai sofrer.' (...) Porque nós temos um governante, é Jesus Cristo, a gente sabe que Ele vai vir aqui tirar todo o sistema de governo e restabelecer o Dele".

A noção de hereditariedade das doenças para a biomedicina remete à herança genética, representação compartilhada por Jair para explicar a doença. No relato acima, se sobrepõe a ela a concepção valorativa religiosa que a enfermidade assume para o crente.

Entende-se que a queda de Adão e Eva legou aos homens os males físicos: a doença e a morte; e o mau moral, o pecado. A ideia de um mal congênito da humanidade fica mais clara quando o informante define o que é saúde:

"Se eu falar para você que ninguém tem saúde suficientemente, não! Não como gostaria que fosse, você não sentir nenhum mal-estar (...) Então a saúde não é só você estar bem, você ter uma saúde perfeita é você ter certeza de que não vai sentir dor, canseira, mal-estar, você não vai precisar de nenhum corretivo".

Seguindo esse raciocínio, a saúde perfeita apenas é possível mediante a salvação da alma mortal, isto é, da pessoa que morre 19 , retornando o homem a sua perfeição original, com a certeza de que não existirão pecado, sofrimentos, doenças e morte na vida humana.

Jair agrega outras causas concomitantes à enfermidade: o hábito de fumar e preferências alimentares rotineiras pelos alimentos gordurosos e o excesso de sal, afastados das normas médicas, prescritas para lidar com a hipertensão e as enfermidades cardiovasculares, como a dieta hipossódica, desprovida de alimentos gordurosos e rica em alimentos fibrosos, como as frutas e verduras. Informado pelos médicos e profissionais de saúde sobre os efeitos negativos daqueles hábitos sobre a sua saúde, ele os traduz como acúmulos negativos dos próprios comportamentos, permeando as explicações da experiência com a enfermidade cardíaca e a "pressão alta".
A orientação religiosa e suas interferências nos tratamentos

A orientação religiosa está presente no modo como se realizou a cirurgia cardíaca de Jair, sobretudo, referente à transfusão sanguínea. Sabe-se que as Testemunhas de Jeová rejeitam a doação e transfusão de sangue, mesmo quando esta se faz necessária.

Assim ele informou aos médicos ser testemunha de Jeová, reafirmando e esclarecendo a sua rejeição à transfusão sanguínea:

"Desde a primeira vez que eu fui ao hospital da PUCC, que eu fiz o cateterismo, disse que era Testemunha de Jeová. O médico falou: 'precisa operar com urgência, só que os seus glóbulos vermelhos estão com o nível muito baixo e vai ter problema. Você vai precisar de sangue se for fazer".

"Nós temos um cartão. Está escrito lá: testemunha de Jeová: não usa sangue. Nós temos um documento, até mesmo se eu tivesse desmaiado, chegasse desmaiado em qualquer lugar! Todas as Testemunhas de Jeová batizadas portam esse documento. Está escrito aqui. É bem visível: não aplique sangue. Quando você abre ele, está vendo aqui: recuso, exceto alguns expansores do plasma, aí vem aqui, hemodiluição, máquina coraçãopulmão (...) eritropoetina que eu tomei".

Ressalta-se o conhecimento do informante das diversas técnicas alternativas à transfusão sanguínea, como a eritropoetina, hormônio endógeno secretado pelos rins, cujas formas recombinantes são utilizadas no tratamento de portadores de problemas renais crônicos submetidos à hemodiálise e que apresentam anemia permanente. Atua como estimulante da produção dos glóbulos vermelhos, promovendo o aumento da oxigenação dos tecidos 20 .

Entendido científica e socialmente como fluído mantenedor da vida, ao sangue é atribuído universalmente valor simbólico ambíguo. Positivamente, significa força, saúde, vida, a família, solidariedade e nação; o sangue sendo concebido como portador de elos e características positivas que agregam e qualificam os homens: o "sangue bom" 21.

Em sua simbologia negativa, o sangue pode trazer doenças, morte, se ligando às guerras, epidemias, ao "mau gênio", àquilo que segrega os homens e os desqualificam, excluindo-os do convívio em sociedade por acionar medos sociais e íntimos e reações inesperadas: o "sangue ruim".

As testemunhas de Jeová compartilham desse duplo significado atribuído ao sangue. Partindo de uma leitura peculiar dos textos bíblicos, não comungada por outras religiões de matriz protestante, entendem o sangue como sinônimo 
da vida, e por extensão da própria pessoa, isto é, da alma mortal.

A interdição a determinados usos do sangue baseia-se, segundo essa visão, em mandado divino expresso em várias passagens bíblicas, como em Gênesis e nos Atos dos Apóstolos, onde se evoca a simbologia negativa do sangue: na primeira, o ato fratricida de Caim remete ao exílio imposto ao povo de Deus, à diáspora, o sangue representando aquilo que separa o homem do divino 19 . Na segunda, alerta-se sobre as impurezas que ele pode trazer por meio da alimentação, pertinentes à ideia de uma ordem física e moral que se interpenetram 22 . Visto que a fronteira entre o humano e o divino se baseia em uma concepção particular da pessoa, o mal é o sangue estranho (de pessoas e animais) que adentra o corpo, corrompendo-o física e moralmente, afastando, consequentemente, o homem da vida eterna.

Já em Levítico e no Evangelho de Mateus apresenta-se a simbologia positiva do sangue: as oferendas de sangue feitas nos altares dos templos antigos, bem como o sacrifício de Cristo, propiciaram a remissão dos pecados, e este último, considerado atualmente pelas testemunhas de Jeová como o único uso correto do sangue, possibilitou ao homem conquistar a vida eterna, ou seja, o retorno ao convívio com a divindade 19 .

O pertencimento ao grupo religioso estabelece os laços identitários entre as testemunhas de Jeová, não redutíveis às atividades realizadas no espaço de culto, nomeado por eles Salão do Reino, nem às pregações em locais públicos, expande-se numa rede colaborativa centrada na questão do sangue. Há um grupo de fiéis encarregado de distribuir nos hospitais material explicativo sobre as alternativas disponíveis à transfusão sanguínea, como esclarece Jair:

"A gente tem documentação, tem DVD e CD, e é feito um acompanhamento. Todos os hospitais recebem, a UNICAMP [Universidade Estadual de Campinas] recebe, a PUCC recebe. Tem uns irmãos qualificados que vão lá, que a gente chama de 'Comissão de Ligação para Hospitais'. Esses irmãos conversam com os médicos, explicam, apresentam o DVD, apresentam as situações. Tanto é que no meu caso o médico falou: 'a eritropoetina nós não temos aqui, mas se você procurar o irmão responsável pelo Salão, eles têm, a associação fornece'. Como é uma coisa que todas as Testemunhas de Jeová conhecem a associação de medicina autorizou a gente a comprar a eritropoetina. O remédio não é muito conhecido, é restrito ao hospital".

A cirurgia de Jair foi realizada sem transfusão sanguínea, mediante técnicas alternativas usadas pelos médicos:

"Então, os médicos da PUCC falaram que, como eles foram até os Estados Unidos, fizeram um curso para ver como se fazia cirurgias sem usar sangue. A minha cirurgia do coração foi sem uso de sangue (...) Foi feita aquela hemodiluição, que é uma máquina igual à que faz hemodiálise. $O$ médico usa o mesmo processo e faz toda a cirurgia com o próprio sangue do paciente; só que numa cirurgia da Testemunha de Jeová que não vai usar sangue, o que ele faz? O médico não pode chegar lá e cortar sem olhar. Ele terá que acompanhar, cortar mais devagar, tomar cuidado com as veias, para não romperem".

Estas técnicas, segundo o informante, contribuíram para o sucesso da sua cirurgia. Porém, é à fé, à proteção divina que recorre para explicar o êxito da cirurgia e do pós-operatório:

"Tinha um médico que falou: 'normalmente nessas cirurgias há transfusões, vai ser muito difícil você pelo SUS encontrar um médico que faça' Mas graças a Jeová, nós conseguimos da equipe da PUCC fazer a cirurgia sem sangue. Ele colocou em nosso caminho uma equipe excelente! A gente sempre faz uma oração pedindo. E Ele sempre colocou ótimos médicos (...) Então a gente fala: 'vou obedecer ao que Deus disse'. Então, quando você começa a fazer o que é correto do lado Dele, Ele começa a te proteger (...) Porque o médico fala assim para você: 'e você não usar sangue, você vai morrer' (...) Agora, se vocêfica com um certo receio, então põe o sangue, você diz o quê para Deus? A minha fé, tudo o que o Seu Filho fez, dar a vida perfeita Dele para resgatar toda a humanidade, porque Jesus Cristo veio e restabeleceu essa ligação da humanidade com Deus, aí você fala para Deus assim: 'tudo o que Você fez não serviu de nada, porque quem vale mais é o médico'. Ele fala: “'então, a partir de hoje você está separado de mim, jogado à própria sorte"”.

Essa fé ativa não se intimida diante dos prognósticos seculares que lhe são contrapostos, antes, são eles motivos da sua provação. Trata-se de uma questão de consciência individual, uma relação pessoal estabelecida com a divindade baseada no cumprimento do dever a ela dispensado, cabendo ao fiel, como prova devocional, entregar a Deus o resultado de suas ações, não lhe sendo imputada, contudo, ausência de responsabilidade. Em síntese, seus atos se estruturam na ética de convicção religiosa 23 .

Após sessenta dias da cirurgia, Jair retornou às suas atividades normais de trabalho, com excelente recuperação:

"Um médico falou: 'olha, a sua cirurgia foi realizada de um jeito que, em uma semana, parece que foi feita há 20 dias'. Um mês depois da cirurgia, todos que fizeram a cirurgia na mesma época que eu, tiveram problemas e retornaram. No mesmo dia que eu fiz os exames de rotina póscirúrgico o pessoal estava lá. O médico falou as 
sim: 'olha, não tem problema, está tudo em ordem! Fica tranquilo!'. Eu falei para ele, que não foi porque eu fiz a cirurgia que eu parei de trabalhar, continuei a mesma coisa, a minha vida, falei, continuou a mesma coisa. Então, graças a Jeová, tudo foi resolvido".

\section{A rotina de vida após a cirurgia}

O impacto da cirurgia e da enfermidade sobre a rotina cotidiana de Jair não foi significativo, como diz: "continuo a fazer a mesma coisa que fazia antes, a única coisa é que eu já não consigo mais correr como antes, jogar bola, mais de resto, tudo igual".

Não realiza nenhuma atividade física recomendada pelo médico para manter a saúde cardíaca e controlar a hipertensão. Justifica esse comportamento, em parte, pela ausência de tempo, pois o trabalho ocupa-o quase que integralmente, ademais, define o seu corpo como "naturalmente firme" e resistente:

"Os médicos falam que ter uma rotina de exercícios físicos é importante. Eu já não tenho, às vezes eu falo que é falta de tempo, mas poderia estar fazendo academia à noite, né? (...) Falaram que eu tenho que fazer caminhada, tem que fazer um pouco de exercício aeróbico, movimentar o corpo, mas eu não faço (...) Então, o que acontece é que eu ainda estou bem, mas eu sempre fui um cara que tinha aquele problema muscular, a minha musculatura é dura, é rígida. O meu braço não é mole, até um dia eu fui ao massagista, o massagista falou: 'relaxa o braço', falei: 'tá relaxado', então ele disse: 'mas, relaxa...' eu disse: 'mais que isso não vai', e ele até estranhou: 'a sua musculatura é rígida!', ela não é rígida, é firme".

Jair usa os remédios indicados para os seus problemas de saúde. Reitera a manutenção do mesmo ritmo de trabalho de antes, significando para ele, a conduta saudável de conservar o corpo em movimento: "mantenho o ritmo, faço o serviço o tempo todo".

A conduta de vida, segundo Weber 24 , articula-se à forma como as pessoas dão sentido às suas ações e ao mundo, numa convergência contínua entre espiritualidade e materialidade.

Refere-se ele às condutas religiosas difundidas pelo protestantismo, uma das bases da religião do informante. $\mathrm{O}$ autor admite que o calvinismo legou ao protestantismo uma relação "direta" com Deus, significando na prática a racionalização do mundo, com a eliminação do pensamento mágico como forma intermediária à redenção. É a partir deste mundo que o crente experimenta a presença divina em sua vida, porque é desde esta vida que se recebe a confirmação de ser um eleito de Deus.
A racionalização deu à fé reformada uma tendência ascética; o ethos religioso se expressa na vida mundana pela ascese ativa voltada ao trabalho, este concebido como finalidade e dever da vida e como exercício virtuoso do crente: " $a$ vida profissional prova o estado de graça para a consciência humana, expressa no zelo, de forma metódica" 25 (p. 15).

A disposição ascética de Jair para o trabalho e as condutas de saúde se justificam pela sua submissão ao mandado divino; com base em sua fé, as condições favoráveis que possibilitaram a sua cirurgia, a recuperação rápida que teve, e o retorno breve ao trabalho são provas de uma conduta agradável aos olhos de Deus.

A cura é um processo compartilhado em que as representações religiosas intersectam a experiência com a enfermidade e são reiteradas, como relata Jair, na experiência de outro amigo de crença, confirmando a fé na divindade e em seu poder curador:

"Então, tem a questão do sangue que é uma ordem bíblica, que Deus deu lá do princípio. Daí você obedece a Deus, e você como testemunha de Jeová passa a ter o que é importante, que é 'ter fé e acreditar nisso.' Tem um irmão entre nós que sofreu um acidente, ele foi atropelado, precisou amputar o braço, não usou sangue, hoje ele tem uma saúde melhor do que quem usou. Então, a gente tem fé, acredita".

"Você tem que pensar assim: 'fez a cirurgia, resolveu o problema'. Você é cardíaco, mas a sua vida, você tem que trabalhar. Esquece o resto e segue, a cirurgia foi para corrigir, agora é seguir a vida normalmente. Eu voltei igual para minha vida de antes, trabalhando e tudo, porque Deus disse para não usar sangue que ele vai preservar, mas se você fala: "o médico disse para usar", então, em quem você vai acreditar? Quem tem mais poder, $o$ médico ou Deus?".

Não está oculta, todavia, a confiança que o entrevistado deposita na biomedicina como mediadora na resolução do seu problema cardíaco, atribuindo à cirurgia caráter corretivo, e afinando-se à concepção do senso comum que vê as tecnologias médicas, sobretudo aquelas sofisticadas e especializadas disponíveis apenas nos ambientes hospitalares, como capazes de solucionar seus males de saúde 26 .

Segundo a crença professada por Jair, a salvação e cura da alma mortal é tarefa eminentemente individual estabelecida por uma relação pessoal e única com o divino. Tal cosmologia religiosa informa o seu modo de vida e as representações que tem da pessoa e dos tratamentos e cuidados de saúde, ressaltando as singularidades de cada um, pois a cura do corpo também é um processo individual, conforme esclarece: 
“Cada organismo é individual (...) Éo seguinte a doença é a mesma, o vírus é o mesmo, só que no meu corpo uma gripe vai se comportar de um jeito, em você de outro (...) Cada um tem que ter cuidado consigo. Eu falo para as pessoas, eu tomo aquela aspirina para dor de cabeça, para enxaqueca. Eu posso tomar um envelope de dez, para mim não vai fazer efeito. Você tem gastrite, toma meio ou toma uma aspirina e passa mal, então você vê isso".

A representação dos cuidados e tratamentos individualizados de saúde radicada na concepção de que as enfermidades se desenvolvem distinta e variavelmente de uma pessoa para outra se aproxima, por afinidade, à lógica clínica. Para esta, o corpo é representado como “individualidade complexa" 27. Nas representações do processo saúde-enfermidade do informante essas lógicas não são excludentes entre si, antes, se complementam.

\section{Conclusão}

A análise da experiência de Jair de momentos específicos do seu adoecimento mostra aproximações e distanciamentos entre visões de mundo distintas. De um lado, a representação da cura e salvação como eventos singulares aproximase da lógica individualista da clínica biomédica. De outro, o entendimento da origem dos sofrimentos e doenças como mal coletivo remete à lógica holística das representações religiosas. A concepção particular dada ao sangue pelas testemunhas de Jeová possibilita o intercâmbio entre as dimensões física e moral, individual e coletiva, promovendo a coexistência de lógicas e visões de mundo diferentes.

A crença religiosa de Jair faz com que tenha uma representação peculiar da pessoa, que não envolve apenas a materialidade imediata do corpo, transcendendo-a à medida que esta ocupa lugar de destaque em sua visão escatológica da existência humana. A doença é, simultaneamente, mal físico e moral, trazendo em si o significado da queda original dos primeiros humanos criados por Deus, repercutindo em sua descendência como pecado, sofrimento, doença e morte. Entretanto, quando ele explica as causas da enfermidade evidencia relações com o saber biomédico: o estilo de vida (alimentação, estresse e tabagismo) e a hereditariedade associados às explicações recorrentes do saber popular, como o nervoso, se auto imputando a responsabilidade pela doença que o acomete.
O adoecimento não trouxe mudanças significativas em sua rotina de vida, e o pertencimento ao grupo religioso das Testemunhas de Jeová o auxilia a conformar uma identidade não restrita ao ambiente de culto, excede-o à medida que é reiterada no espaço biomédico, sobretudo quanto à proibição do uso do sangue na cirurgia, reafirmando socialmente a sua crença.

Cumpre as recomendações contidas na Bíblia, a ascese voltada ao trabalho reveste-se de virtude redentora para a salvação da alma mortal, expressando desde esta vida que se é um eleito de Deus pela saúde do corpo e a consequente disposição para o trabalho. Não se descura das orientações médicas, entendendo-as como complementares ao seu tratamento. Toma regularmente os medicamentos necessários para o controle de suas enfermidades, valoriza as intervenções biomédicas sem prescindir de suas crenças e explicações relacionadas à saúde/ doença, modeladas segundo a moralidade cristã da fé reformada.

Baseado em sua crença religiosa, Jair acredita que seus problemas de saúde são antes provações impostas ao crente, uma vez que a saúde perfeita somente será possível com o advento da salvação. De um lado, manter uma postura positiva diante das adversidades significa passar pela provação da doença, obedecendo às ordenações divinas, pois apenas a Deus pertence à cura. De outro, a submissão ao divino coloca o fiel em posição favorável, trazendo-lhe a esperança e a certeza da cura. Caso contrário prova-se a insuficiência da fé.

Essas considerações auxiliam a compreender parcela das representações e da experiência de Jair com suas enfermidades em momentos significativos e críticos, sobretudo da doença cardíaca, uma das consequências da hipertensão arterial sistêmica não controlada, segundo o saber biomédico. No relato do informante sobressai muito mais a primeira do que a hipertensão, com a qual considera poder conviver normalmente, desde que não se exacerbe e interrompa o seu silêncio. 


\section{Colaboradores}

Os autores trabalharam conjuntamente em todas as fases de preparação do artigo.

\section{Agradecimentos}

Os autores agradecem à FAPESP pelo auxílio financeiro concedido.

\section{Referências}

1. Montero P. Da doença à desordem: a magia na umbanda. Rio de Janeiro: Edições Graal; 1985.

2. Rabelo MC. Religião e cura: algumas reflexões sobre a experiência religiosa das classes populares urbanas. Cad Saúde Pública 1993; 9:316-25.

3. Laplantine F. Antropologia dos sistemas de representações da doença: sobre algumas pesquisas desenvolvidas na França contemporânea reexaminadas à luz de uma experiência brasileira. In: Jodelet D, organizador. As representações sociais. Rio de Janeiro: Eduerj; 2001. p. 241-59.

4. Gomberg E. Hospital de orixás: encontros terapêuticos em um terreiro de candomblé. Salvador: Edufba; 2011.

5. Mota C, Trad LAB, Villas Boas MJVB. O papel da experiência religiosa no enfrentamento de aflições e problemas de saúde. Interface Comun Saúde Educ 2012; 16:665-75.

6. Mello ML, Oliveira SS. Saúde, religião e cultura: um diálogo a partir das práticas afro-brasileiras. Saúde Soc 2013; 22:1024-35.

7. Rabelo MC. Religião e a transformação da experiência: notas sobre o estudo das práticas terapêuticas nos espaços religiosos. Ilha Revista de Antropologia 2007; 7:124-45.

8. Castro EG. A torre sob vigia: as Testemunhas de Jeová em São Paulo (1930-1954) [Dissertação de Mestrado]. São Paulo: Programa de Pós-graduação em História Social, Universidade de São Paulo; 2007.

9. Separavich MAA. Saúde masculina: representação e experiência de homens trabalhadores com o corpo, saúde e doença [Tese de Doutorado]. Campinas: Programa de Pós-graduação em Saúde Coletiva, Universidade Estadual de Campinas; 2014.

10. Canesqui AM. Estudo de caso sobre a experiência com a "pressão alta". Physis (Rio J.) 2013; 23:903-24.

11. Pierret J. The illness experience: state of knowledge and perspectives for research. Sociol Health Illn 2003; 25: 4-22.

12. Bury M. Chronic illness as biographical disruption. Sociol Health Illn 1982; 4:167-82.

13. Barsaglini RA. As representações sociais e a experiência com o diabetes: um enfoque socioantropológico. Rio de Janeiro: Editora Fiocruz; 2011.
14. Stake RE. Case studies. In: Denzin N, Lincoln Y, editors. The handbook of qualitative research. 2nd Ed. London: Sage Publications; 2000. p. 435-54.

15. Bardin L. Análise de conteúdo. Lisboa: Edições 70; 1979.

16. Saad JA, Garcia JCF, Guimarães JI. Diretriz para a realização de exames diagnósticos e terapêuticos em hemodinâmica. Arq Bras Cardiol 2004; 82 Suppl I:1-6.

17. Duarte LFD. Da vida nervosa nas classes trabalhadoras urbanas. Rio de Janeiro: Jorge Zahar Editor; 1986.

18. Canesqui AM. A hipertensão do ponto de vista dos adoecidos. In: Canesqui AM, organizadora. Olhares socioantropológicos sobre os adoecidos crônicos. São Paulo: Editora Hucitec; 2007. p. 87-110.

19. Sociedade Torre de Vigia. O que a Bíblia realmente ensina. São Paulo: Sociedade Torre de Vigia; 2013.

20. Bento RMA, Damasceno LMP, Aquino Neto FR. Eritropoetina humana recombinante no esporte: uma revisão. Rev Bras Med Esporte 2003; 9:181-90.

21. Steffen M. Respostas públicas, sucesso e fracasso no gerenciamento de riscos. DeMA Desenvolvimento e Meio Ambiente 2002; 5:39-48.

22. Douglas M. Pureza e perigo: ensaios sobre as noções de poluição e tabu. Lisboa: Edições 70; 1991.

23. Weber M. Ciência e política: duas vocações. São Paulo: Martin Claret; 2001.

24. Weber M. A ética protestante e o espírito do capitalismo. São Paulo: Companhia das Letras; 2004.

25. Löwy M. Redenção e utopia: o judaísmo libertário na Europa Central. São Paulo: Companhia das Letras; 1989

26. Canesqui AM. Consumo e avaliação de serviços de saúde. In: Spinola AWP, Sá ENC, Westphal MF, Adorno RCF, Zioni F, organizadores. Pesquisa social em saúde. São Paulo: Cortez Editora; 1992. p. 175-205.

27. Foucault M. O nascimento da clínica. Rio de Janeiro: Forense Universitária; 1977. 


\section{Abstract}

This article, the byproduct of a larger research project, presents a case study of a Jehovah's Witness with hypertension and cardiac problems. Semi-structured interviews were used to reconstruct the individual's illnes. experience: diagnosis, treatments, and cure, focusing on pervasive religious social representations, lending meaning to his own life and to the physical and moral suffering and disturbances involved in this process.

Faith Healing; Health-Disease Process; Religion

\section{Resumen}

Este artículo, subproducto de una investigación más amplia, aborda un estudio de caso de un enfermo de hipertensión y con problemas cardíacos que profesa la religión de los Testigos de Jeová. Mediante entrevistas con guion semiestructurado se reconstituyeron los relatos del entrevistado sobre la experiencia con el proceso de enfermedad: diagnóstico, tratamientos y cura enfocando las representaciones sociales religiosas que la permean, proporcionando sentido a la propia vida y a los sufrimientos y perturbaciones físicas y morales implicadas en este proceso.

Curación por la Fé; Proceso Salud-Enfermedad; Religión

Recebido em 19/Fev/2015

Versão final reapresentada em 18/Jun/2015 Aprovado em 01/Jul/2015 